\title{
DESIGN OF A CONSISTENT INTERDISCIPLINARY AND DUAL FACULTY CAPSTONE EXPERIENCE AT THE UNIVERSITY OF MANITOBA
}

\author{
W.C.D. DeGagne* and Paul E. Labossiere, \\ Faculty of Engineering, University of Manitoba, Winnipeg. MB, Canada R3T 5V6 \\ *William.degagne@umanitoba.ca
}

\begin{abstract}
One of the most effective and efficient ways for an engineering program to facilitate compliance with the Canadian Engineering Accreditation Board (CEAB) accreditation criteria is through capstone design projects and courses, [1]. Currently, the University of Manitoba Faculty of Engineering has several capstone design courses; however, each is independently focused on its own respective discipline. The resulting educational experience for students, though rigorous and challenging, is maintained within the boundaries of the students' engineering discipline, thereby neglecting to provide the opportunity for students to work with people from multiple disciplines and across different faculties. This style/mode of education, where students work in silos, arguably does not reflect real world engineering. Program representatives from the Faculty of Engineering at the University of Manitoba agree that the capstones should be more reflective of real life situations.

For this paper, we were hoping to present the research results of a pilot interdisciplinary capstone that was to be launch in the winter of 2017. Unfortunately, the pilot course was not offered because of low student enrollment. So we decided to take an innovative and creative approach to the research. Since, at the University of Manitoba, the Dean of Engineering is also the Dean of the Faculty of Architecture, rather than team with an outside industry focus group, we decided to develop a holistic course with the Faculty of Architecture. The Dean supports this strategy. Interdisciplinary courses are most important because they "...articulate the difference between educational problems and workplace problems" [2]. And allow "(students) persons from different disciplines to work collaboratively and are integrated to combine their knowledge to solve a problem"[3].

This paper explores and explains how that Engineering/Architecture Multidiscipline Capstone and Dual Faculty course will be developed, touches on the early stages of its initiation and implementation, and outlines how the success of the new course will be evaluated.
\end{abstract}

Keywords: Interdisciplinary; multidisciplinary; capstone course; pilot program, dual faculty.

\section{INTRODUCTION}

From last year's paper, it was determined through the focus groups and research that this interdisciplinary initiative will be a technical elective offered as pilot course on a voluntary basis between the mechanical and electrical engineering programs at the University of Manitoba. These two disciplines were chosen to launch the initiative because they have worked together closely before and are critical components of any building project design and construction. It was then to be expanded to include the other disciplines after performance qualitative and quantitative evaluations were completed. The course was advertised and was to be launched in January 2017. Eight (8) to twelve (12) students were required to enroll for the initial offering to be viable. The interdisciplinary capstone was scheduled as a late afternoon class to respect students' established timetables and the existing course offering formats. The course would consist of two hours of lectures and three hours of tutorials per week for site visits and meetings with the external group.

An Internal Engineering Faculty Group was formed to provide theoretical instruction on how a project is developed. To insure integration of the learning, the Interdisciplinary teams were to present design lectures to their fellow classmates. This Charrette process was used where students would research each discipline design and present it, in a seminar format, to the class as a lecture. The External Group, which consisted of an actual development business Team, which included: the project Architect; sub-consultants; the developer, and; the general contractor, was to provide the practical application of the design, sharing all the project documentation with the class.

The course structure was to be comprised of a five-part deliverable evaluation including the following stages: review of project criteria; submission of design questions; responses to design questions; project scope change, and; design to accommodate the scope change. The external group had named an actual condominium construction as 
the project that would be developed through the course. The internal group representatives had committed to providing design advisory instruction for the winter 2017 course offering.

It was anticipated that the external group would have between 10 and 15 hours contact time with the students over the winter session. To facilitate the external group's tight time frames, meetings with the class were to be conducted at the architect's office. At the final stage of course, the internal disciplines will present their designs to the external team for adjudication. [5].

Throughout the 2016 fall session, internal and external focus group meetings were held to develop the structure, format, and schedule for the winter 2017 Cross Discipline pilot course. See Appendix 1 MECH 4310 Contemporary Topics in Mechanical Engineering-Interdisciplinary Design: Course Structure. The course advertising took place in the fall: bulletin board notifications; third and fourth year students were contacted via E-mail, and; short presentations were carried out in several undergraduate classes. Unfortunately, because of limited enrollment, the course was cancelled, and it was decided thereafter to renew efforts for the following year and take a holistic approach in collaboration with the Faculty of Architecture.

\section{BACKGROUND}

For the purpose of this paper, a capstone course is defined as "...a project-based learning experience that involves engineering practice through a significant design project whereby student teams meet specific client needs through a creative, iterative, and open-ended design process" [4].

At last year's Conference, we presented our research into recent publications, focus group discussions, and how other institutions approach this challenge, and have identified the following capstone design course key framework goals:

- Should be implemented and managed through a central unit such as the University of Manitoba's Centre for Engineering Professional Practice and Engineering Education

- Should be offered in the final year of a four year Engineering program and should be offered over two terms for at least six (6) credit hours

- Project team members should be from different engineering disciplines and possibly from different faculties

- There must be an strong affiliation with industry or community service
- Student performance evaluations must be based on deliverables with a mechanism for internal team peer assessment

- The final submission should consist of an industrial design report including a design prototype

Last year's paper focused on how the Faculty of Engineering at the University of Manitoba might amalgamate the courses based on the identified goals and create a meaningful capstone design experience for undergraduate students, better prepare them for professional employment, and enhance compliance with the CEAB Graduate Attributes requirements. Finally we presented an approach that allowed the initiative to be piloted on a trial basis as a voluntary option between the Mechanical and Electrical programs at the University of Manitoba. The above framework goals were applied to the proposed pilot course offering.

As an extension of last year's submission, we were going to present the findings from the pilot course design which was to be initiated. Unfortunately, the pilot course was not offered in the 2017 winter session because of low enrollment. So we decided to take an innovative and creative approach to the research. Rather than team with an outside industry development focus group, we decided to develop a holistic course with the Faculty of Architecture. This approach is facilitated by the Dean of Engineering who also serves as the Dean of the Faculty of Architecture, and supports an Engineering/Architectural interdisciplinary dual faculty capstone initiative/strategy. This paper explores how that Engineering/Architecture Multidiscipline Capstone and Dual Faculty course will be developed and evaluated.

\section{METHODOLOGY}

Besides the research conducted for the CEEA 2016 paper submission, in accordance with University of Manitoba policies, applications were made to the Research Ethics Board as well as the Survey Review Committee. To protect the rights and welfare of human participants in research studies conducted at, or under the auspices of the University of Manitoba, prior ethics review and approval is required by a Research Ethics Board (REB), [6]. In addition, the purpose of the Survey Review Committee is to review proposed surveys, focus groups, and interviews of students, faculty, staff, and alumni to assess quality, timing, adherence to privacy legislation, and to evaluate the usefulness and applicability of them in achieving the University of Manitoba's strategic objectives, [7]. 
The methodologies that will be used to develop, implement, and evaluate the Eng/Arch capstone course include qualitative and quantitative analyses.

Specially, a January, 2018 before and an April, 2018 after Eng/Arch student surveys will be conducted. The results of the questionnaire will be compared and contrasted to discover how effective students learned, whether their personal course goals were achieved and what could be adjusted to accommodate a better learning environment. From a comparative perspective, an additional student survey will performed on an undergraduate technology and ethics course to determine if teaching and learning techniques from either course could be applied in the other course to make the teaching more meaningful. The same survey will be given to all three classes, and is shown in Appendix 2, Interdisciplinary Engineering and Architecture Capstone Experience Pilot Course Evaluation Performance Survey. The surveys are structured to determine if students perceive that they have acquired some of the CEAB attributes as a result of taking the course.

Because unbiased research can be performed on students in an unrelated course, a case study analysis will be conducted on a graduate course in engineering design philosophy. One of the case study research question will be "How can the successful teaching techniques of a matured graduate course be applied to an undergraduate multidisciplinary/dual faculty course?" Further research questions will be developed and presented in the next paper.

Peer evaluations in the winter of 2018 will also be employed as a methodology to determine and assess further course development strategies. See Appendix 3, Eng/Arch Interdisciplinary and Dual Faculty Capstone Course Peer Evaluation Winter 2018. Students with low peer reviews will be identified and engagement trends determined to provide a better learning environment.

Students will also provide weekly reflective learnings, which will be reviewed and general trends noted. See Appendix 4, Eng/Arch Interdisciplinary and Dual Faculty Capstone Course Reflective Learning. These trends will provide student feedback on their learning and allow the instructors to communicate with students in a nonthreatening environment. Student suggestions on the course delivery will be recorded and implemented.

\section{FINDINGS}

Since this paper is focusing on how the extended engineering and architecture course will be developed, the findings presented here are brief, and a more detailed

CEEA17; Paper 118

University of Toronto; June 4-7, $2017-3$ of $5-$ analysis will be presented in a later paper after the research is completed.

\section{NEXT STEPS}

For now the template used as a basis for the Eng/Arch course development structure will be comprised of a fivepart deliverable evaluation including the following stages: review of project criteria; submission of design questions; responses to design questions; project scope change; design to accommodate the scope change. As referenced above see Appendix 1 MECH 4310 Contemporary Topics in Mechanical Engineering-Interdisciplinary Design: Course Structure. The Architectural Focus Group has named a boutique hotel project as the project that will be developed through the course. The Engineering Focus Group representatives have committed to providing design advisory instruction for the upcoming winter 2018 course.

At this time it is anticipated that the external group will have between 10 and 15 hours contact time with the students over the winter session. To facilitate the external group's tight time frames, meetings with the class will be conducted at the architect's office. At the final stage of course, the internal disciplines will present their designs to the external team for adjudication.

\section{CONCLUSIONS}

This paper has focused on how a multidisciplinary Engineering and Architectural capstone course has been proposed for the Faculty of Engineering and the Faculty of Architecture at the University of Manitoba in order to create a more meaningful capstone design experience for undergraduate students, better prepare them for professional employment, and enhance compliance with the CEAB Graduate Attributes requirements.

From the development of this conference paper, I have learned the following important lessons:

- Course work material such as the following processes: peer evaluations; weekly reflective learnings, and; personal course diaries and logs can be extremely useful to develop a dual faculty course

- To stay on task, I need to create and follow and review a rigid course log to stay focused on the big picture

- I look forward to developing the engineering and Architecture capstone course and nurturing it along the way to create a meaningful and practical course that Engineering and Architectural students will benefit from taking.

\section{Acknowledgements}

The authors would like to thank the following individuals:

Douglas Ruth, P. Eng., Ph.D. 
Proc. 2017 Canadian Engineering Education Association (CEEA17) Conf.

Jillian Seniuk Cicek, Ph.D. Candidate

Dr. Marcia Friesen, Associate Dean Faculty of Engineering

Dr. Jonathon Beddoes, Dean Faculty of Engineering and Faculty of Architecture

The Internal Interdisciplinary Team, including: Dr. Kristopher Dick; Dr. Dimos Polyzois; Dr. Athula Rajapakse, and; Dr. Robert Derksen

External Industry Team including: Carolyn Geddert; P. Eng., Ted Geddert; Sasa Radulovic; Mark Penner, and; Julien Lavergne

Architectural Focus Group: Dr. Carlos Rueda, and; Neil Minuk

\section{References}

[1] Engineers Canada (2012), Canadian Accreditation Engineering Board Accreditation Criteria and Procedures

[2]Aditya Johri, and Barbara M. Olds, The Cambridge Handbook of Engineering Education. New York, NY: Cambridge University Press, 2014, pp. \{ISBN:

[3] Maura Borrego and Lynita K. Newswander, "Characteristics of successful cross-discipline engineering education collaborations, " Journal of Engineering Education, vol. 97, no. 2, pp. 123-134, 2008.

[4] $\mathrm{U}$ of $\mathrm{T}$ definition for capstone https://www.mie.utoronto.ca/undergrad/capstone downloaded May 2,2016

[4]

[5] W.C.D. DeGagne, and Paul Labossiere, "Development and Implementation of a Cross Discipline Capstone Design Experience at the University of Manitoba" in Proc. CEEA Canadian Engineering Education Conf., CEEC16, (ed.) (Dalhousie University, Halifax, Nova Scotia; 19-22 June 2016), [6] http://www.umanitoba.ca/research/orec/ethics/human_ethics_in dex.html May 4, 2017

[7] 2017

\section{APPENDIX 1: MECH 4310 CONTEMPORARY TOPICS IN MECHANICAL ENGINEERING- INTERDISCIPLINARY DESIGN: COURSE STRUCTURE}

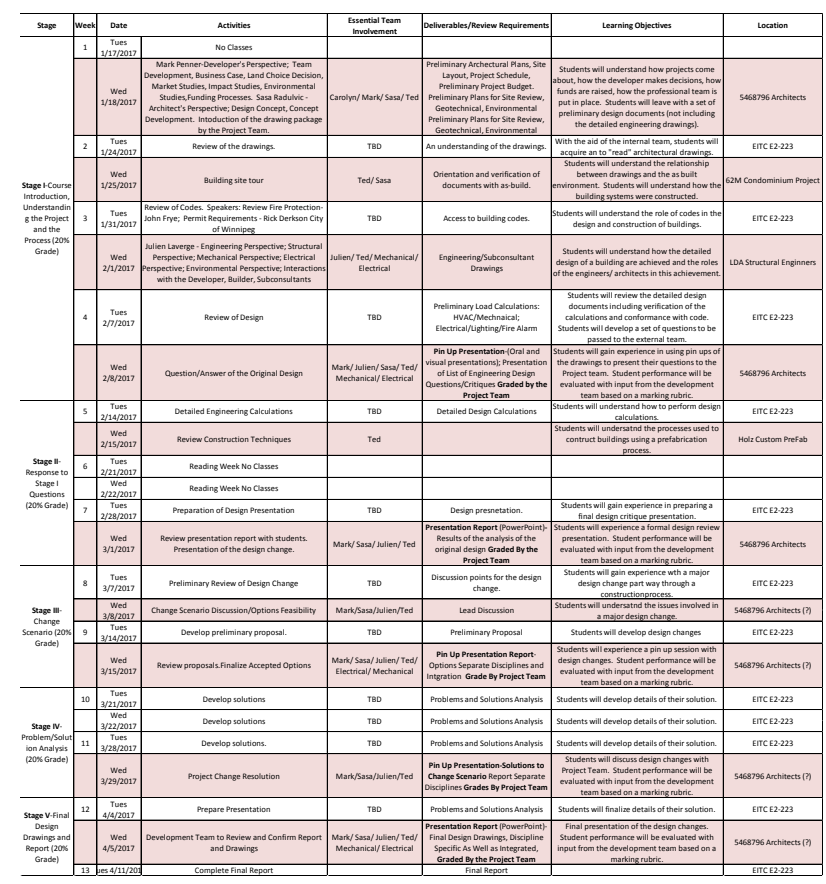

\section{APPENDIX 2: INTERDISCIPLINARY ENGINEERING AND ARCHITECTURE CAPSTONE EXPERIENCE PILOT COURSE EVALUATION PERFORMANACE SURVEY}

For brevity, the preamble which contains research purpose, ethics approval requirements, survey processing guidelines, and additional instructions, has been omitted here.

Instructions: Please circle the letter or letters of your choice or choices.

1. What years of the Engineering program are you currently enrolled? $1,2,3,4,+5$

2. What is your Engineering Discipline? Biosystems, Civil, Electrical and Computer, or Mechanical

3. Have you previously taken any of the following discipline specific capstone courses:

(Yes/No)
a. MECH 4860 Engineering Design
b. ECE 4600 Group Design Project
c. CIVL 4590 Capstone Design Project
d. BIOE 4580 Design Trilogy II
e. BIOE 4580 Design Trilogy III;

4. Would you consider taking an interdisciplinary capstone course?

Never/Not Likely; Don't Know; Likely/Definitely

5 . How do you determine your course learning success?

Select as many as applicable: 
a. Marks

b. Positive application of course material to everyday life

c. Positive application of course material to job (summer/coop, etc.)

d. $\quad$ Other (Please specify):

6. How do you learn most effectively and efficiently? (Select as many as applicable)

a. Researching on your own

b. Researching in teams,

c. Completing assignments on the material covered

d. Giving lectures to fellow class mates

e. Working with industry sponsors

f. Open ended discussion lectures

g. Others methods please specify

7. For students who have already completed an interdisciplinary capstone design course, were you better able to solve complex engineering problems based on the course learnings?

Never/Not Likely; Don't Know; Likely/Definitely

8. For students who have already completed an interdisciplinary capstone design course, were you better able to design solutions for complex, open-ended engineering problems with appropriate attention to economic, environmental, cultural, and societal considerations based on the course learnings?

Never/Not Likely; Don't Know; Likely/Definitely

9. For students who have already completed an interdisciplinary capstone design course, were you able to communicate complex engineering concepts within the profession and with society at large? (This includes your student interdisciplinary capstone team, the internal focus group, as well as your external focus group.)

Never/Not Likely; Don't Know; Likely/Definitely 10. For students who plan to complete the interdisciplinary capstone course, do you expect that completing the course will give you an ability to solve complex engineering problems based on the course learnings?

Never/Not Likely; Don't Know; Likely/Definitely 11. For students who plan to complete the interdisciplinary capstone course, do you expect that completing the course will give you an ability to design solutions for complex, open-ended engineering problems with appropriate attention to economic, environmental, cultural, and societal considerations based on the course learnings?

Never/Not Likely; Don't Know; Likely/Definitely 12. For students who plan to complete an interdisciplinary capstone design course, do you expect that completing the course will give you an ability to communicate complex engineering concepts within the profession and with society at large? (This includes your student interdisciplinary capstone team, the internal focus group, as well as your external focus group.)

Never/Not Likely; Don't Know; Likely/Definitely
APPENDIX 3: ENG/ARCH INTERDISCIPLINARY AND DUAL FACULTY CAPSTONE COURSE PEER EVALUATION - WINTER 2018

In the space below, honestly evaluate the other members of your class using the provided criteria and ranking system. In the case where you feel a group member's contribution was unsatisfactory, please provide an explanation in the comments.

Evaluations are to be submitted by email to Bill DeGagne and the TAs no later than Midnight on Friday, April XX, 2016.

Evaluator's Name:

Class Member 1:

1. Carried a fair share of the workload

2. Completed all assigned tasks with a high degree of quality

3. Completed all assigned tasks within a timely manner

4. Was overall pleasant/easy to work with

5. Was overall a valuable contributing member Additional comments (optional):

\section{APPENDIX 4: ENG/ARCH INTERDISCIPLINARY AND DUAL FACULTY CAPSTONE COURSE REFLECTIVE LEARNING - WINTER 2018}

Students will submit Reflective Learning (RL) comments. Each should contain your personal reflection, showing your understanding and critical thinking of one or more of the following:

- How the specific week(s) course work applies to you, and lessons learned

- How the week(s) course work could be adapted to your work or personal context

- How the week(s) course work may be relevant to you or your specific field.

Whatever you choose to write should contain some depth of thought - a very personal reflection. Each RL should be concise and between 100 to 150 words. Reflective learnings longer than 150 words may not be marked. 